\title{
Construction of the POT1 promoter report gene vector, and the effect and underlying mechanism of the POT1 promoter in regulating telomerase and telomere length
}

\author{
LIANG ZENG $^{1}$, YUE-LI WANG ${ }^{1}$, FA WANG ${ }^{1}$, SHI-QUAN CUI ${ }^{1}$, LIANG HU ${ }^{1}$, DI-NAN HUANG ${ }^{2}$ and GAN HOU ${ }^{2}$ \\ ${ }^{1}$ Department of Basic Medicine, Institute of Biochemistry and Molecular Biology, Guangdong Medical University, \\ Zhanjiang, Guangdong 524023; ${ }^{2}$ Department of Clinical Biochemistry, Guangdong Medical University, \\ Dongguan, Guangdong 523808, P.R. China
}

Received December 9, 2015; Accepted May 11, 2017

DOI: $10.3892 / \mathrm{ol} .2017 .7127$

\begin{abstract}
By using human genomic DNA as a template to clone protection of telomere 1 (POT1) promoter gene segments and construct the POT1 promoter luciferase report gene vector (pGL3-Control-POT1-promoter), the association between POT1, and the regulation of telomerase and telomere length was investigated. In the present study, two recombinant luciferase report gene vectors were constructed, which included different regions of the POT1 promoter. The plasmids were transformed into DH5 $\alpha$ and the positive clones were obtained. The two plasmids termed as pGL3-Control-POT1-promoter-1 and pGL3-Control-POT1-promoter-2, were confirmed using restriction enzyme analysis and sequencing. They were separately and transiently transfected into four types of human tumor cells (A549, H460, HepG2 and HeLa). The transcriptional activities of the POT1 promoter were verified using the dual-luciferase assay. The relative expression of POT1 and human telomerase reverse transcriptase (hTERT), and telomere length were analyzed using quantitative polymerase chain reaction in the four types of non-transfected tumor cells. Using SPSS software, correlations between POT1 promoter activity, and POT1 expression, hTERT expression and telomere length were analyzed. Two POT1 promoter fragments (POT1-promoter-1 and -2) were successfully constructed into the pGL3-Control luciferase report gene vector. POT1-promoter-1 exhibited significantly stronger transcription activity compared with POT1-promoter-2. The results of the partial correlation and linear regression analyses were similar: POT1 promoter activity was identified to be significantly and positively correlated with POT1 expression
\end{abstract}

Correspondence to: Professor Gan Hou, Department of Clinical Biochemistry, Guangdong Medical University, 1 Xincheng Road, Dongguan, Guangdong 523808, P.R. China

E-mail: 414786517@qq.com

Key words: POT1, promoter, report gene, luciferase, telomerase, telomere length, tumor cells and telomere length (partial correlation coefficients, both $\mathrm{P}<0.05$; linear regression, both $\mathrm{P}<0.01)$. However, POT1 promoter activity and hTERT expression were significantly negatively correlated (both $\mathrm{P}<0.05$ ). The results obtained in the present study suggest that the POT1 promoter influences telomere length. Furthermore, these data indicated that POT1 promoter activity and POT1, as well as telomere length, may be a useful biomarker for tumor detection and future patient prognosis.

\section{Introduction}

Telomeres were discovered and named by Muller in 1938, and comprise of a repetitive DNA sequence (5'-TTAGGG-3') $(1,2)$. Telomeres are protein-DNA complexes at the ends of eukaryotic chromosomes, which aid in completing the replication of chromosome ends, preventing chromosomes from fusion and chromosome reorganization and degradation (3-5). A previous study reported that telomeres may be involved in gene expression regulation, thus modulating the cell replication process and aging (6). Telomeres are also associated with numerous proteins, including telomeric repeat binding factor (TERF/TRF)1, TRF2, TERF1 interacting nuclear factor 2 (TIN2), protection of telomere 1 (POT1), tripeptidyl peptidase 1 (TPP1) and TERF2 interacting protein. Furthermore, telomere-associated proteins possess functions that maintain the integrity of the chromosome tail and regulate the telomere extension process (7). Telomerase is a ribonucleoprotein complex, which consists of telomerase RNA, a reverse transcriptase subunit (telomerase reverse transcriptase, hTERT) and associated proteins $(8,9)$. Its activation is essential to the continuous proliferation of cells and is involved in malignant tumor proliferation $(10,11)$.

Human POT1 is a housekeeping gene containing a total of 22 exons, which is expressed extensively in human tissues and cells, and its translation begins in the sixth exon. POT1 is located on chromosome 7 (7q31.33) and has a total length of $\sim 120 \mathrm{~kb}$, the cDNA sequence length is $\sim 2631 \mathrm{bp}$ and the coding region is located between bp 24 and 1928 (12). Previous studies have established that POT1-TPP1 in combination with a single-stranded telomeric DNA enhances telomerase 
activity $(13,14)$. In addition, hPOT1 is able to convey the relevant information regarding telomere length that TRF1-TRF2 contains, to the telomeric DNA ends and telomerase, subsequently telomerase is activated, guaranteeing stability of the telomere length $(12,15)$. Veldman et al (16) reported that HeLa telomere stability was decreased significantly following the inhibition of hPOT1 function via RNA interference knockdown, ultimately leading to cell senescence and apoptosis. Armbruster et al (17) demonstrated that mutations to the DAT domain of hTERT restored telomerase activity and extended telomere length following increased expression of POT1 in telomerase-positive cells. However, in cells with low POT1 expression in telomerase-negative cells, telomere length was not affected. This suggests that POT1 has a telomerase-dependent regulatory function on telomere length (17). POT1 regulates telomerase activity via the collaboration with other DNA-binding proteins and as part of telomere protein complexes in mammalian cells. When POT1 expression is increased or decreased, it affects the conformation of the telomere complex, relieving the steric effect and enabling telomere elongation due to POT1 binding with single-stranded telomeric DNA (18). Therefore, it is evident that POT1 exhibits an influence on telomerase activity and the maintenance of telomere length.

In the present study, the transcription activity of the POT1 promoter in 4 tumor cell lines was determined by constructing its sequences with different lengths of the luciferase reporter gene carrier (Fig. 1). In addition, the regulatory mechanism of the POT1 promoter was preliminarily investigated through evaluating its correlation with POT1, telomerase and telomere length.

\section{Materials and methods}

Cell culture. The A549, HeLa, H460 and HepG2 cancer cells were provided by the laboratory of the Guangdong Medical College Institute (Guangdong, China), and were stored in the laboratory of Guangdong Medical College Institute. For all experiments, the four types of cancer cells were plated in Dulbecco's modified Eagle medium (Thermo Fisher Scientific, Inc., Waltham, MA, USA) containing $4.5 \mathrm{~g} / 1$ D-glucose and $10 \%$ fetal calf serum (Zhejiang Tianhang Biological Technology Co., Ltd., Hangzhou, China). All cells were cultured at $37^{\circ} \mathrm{C}$ in a humidified environment containing $5 \% \mathrm{CO}_{2}$.

Plasmid construction. POT1-promoter-1 (-160 to +40$)$ and POT1-promoter-2 (-370 to +90) clone segment primers (Table I) were synthesized by Beijing Genomics Institute (Shenzhen, China). Both primer pairs contained the BglII (5'-GCAGATCT-3') and HindIII (5'-GCAAGCTT-3') endonuclease sites. The genomic DNA was extracted from A549 cells using the MiniBest Universal Genomic DNA Extraction kit (version 5.0; Takara Biotechnology Co., Ltd., Dalian, China), according to the manufacturer's protocol. Then the target fragment was amplified through polymerase chain reaction (PCR) using 2X Taq PCR MasterMix (Tiangen Biotech Co., Ltd., Beijing, China), and recovered using the MiniBest DNA Fragment Purification kit (version 3.0; Takara Biotechnology Co., Ltd.), according to the manufacturer's protocol. The thermocycler conditions for the PCR were as follows: $3 \mathrm{~min}$ at $94^{\circ} \mathrm{C}$; 30 cycles of $94^{\circ} \mathrm{C}$ for $30 \mathrm{sec}, 66^{\circ} \mathrm{C}$ for $30 \mathrm{sec}$ and $72^{\circ} \mathrm{C}$ for $1 \mathrm{~min}$; and $72^{\circ} \mathrm{C}$ for $5 \mathrm{~min}$. Subsequently, the pGL3-control plasmid (Promega Corporation, Madison, WI, USA) and PCR products containing the desired sequence were double-digested with BglII and HindIII, and annealed together using T4 DNA ligase (Takara Biotechnology Co., Ltd.) at $16^{\circ} \mathrm{C}$ overnight. The ligation products were transformed into chemocompetent Escherichia coli $\mathrm{DH} 5 \alpha$ cells (Tiangen Biotech Co., Ltd., Beijing, China) maintained in LB medium (Shanghai Kehua Bio-Engineering Co., Ltd., Shanghai, China) and bacterial culture medium containing ampicillin (Tiangen Biotech Co., Ltd., Beijing, China) to select for the recombinant plasmid-positive colonies. Identification of recombinants with the desired PCR products were confirmed using $1 \%$ agarose electrophoresis and DNA sequencing. The recombinant plasmids were termed as POT1-promoter-1 (pGL3-Control-POT1-promoter-1) and POT1-promoter-2 (pGL3-Control-POT1-promoter-2).

Transfection and dual-luciferase report assays. A total of $0.5-2 \times 10^{5}$ A 549, HeLa, H460 or HepG2 cancer cells/well were seeded in 24 -well plates. After $24 \mathrm{~h}$ incubation at $37^{\circ} \mathrm{C}, 1.5 \mu \mathrm{g}$ of POT1-promoter-1, POT1-promoter-2, pGL3-basic and pGL3-control were mixed with $0.03 \mu \mathrm{g}$ pRL-TK (all Promega Corporation) in $150 \mu 1$ Opti-MEM I ${ }^{\circledR}$ Reduced Serum (Thermo Fisher Scientific, Inc.); the mixtures were separately co-transfected with Firefly luciferase (Fluc)-Renilla luciferase (Rluc) into tumor cells using Lipofectamine ${ }^{\mathrm{TM}} 2000$ (Thermo Fisher Scientific, Inc.). After another $24 \mathrm{~h}$ of incubation at $37^{\circ} \mathrm{C}$, luciferase activity was measured using the Dual-Luciferase ${ }^{\circledR}$ Reporter Assay system (Promega Corporation). Briefly, the culture medium was removed and the cells were washed with cold 1X PBS. Then 1X passive lysis buffer (PLB; $100 \mu 1$; Promega Corporation) was added to the 24 -well plates. The culture plates were agitated at a low speed for $20 \mathrm{~min}$ at room temperature and transferred to clean $1.5 \mathrm{ml}$ centrifuge tubes (in special cases, a cell scraper or pipette was used to repeatedly beat the samples to ensure complete lysis of the samples). Subsequently, Luciferase Assay reagent II (100 $\mu \mathrm{l} /$ well) and cell lysate $(20 \mu 1 /$ well) were added to 96 -well plates, and mixed evenly. The activity of Fluc was detected using a microplate reader with 1-2 sec delay and 5-10 sec reading. Finally, the activity of Rluc was detected following the addition of $100 \mu \mathrm{l}$ Stop\&Glo ${ }^{\circledR}$ reagent (Promega Corporation) for normalization.

RNA extraction and reverse transcription $(R T)$. Total RNA was extracted from each non-transfected sample using TRIzol reagent (Thermo Fisher Scientific, Inc.) and RT was performed according to the FastQuant RT kit protocol (Tiangen Biotech Co., Ltd.). The isolated RNA was used as a template for reverse transcription using the following protocol: Each $20 \mu \mathrm{l}$ reaction contained 5X gDNA buffer, 10X Fast RT buffer, FQ-RT Primer mix, RT Enzyme mix, RNase-free $\mathrm{dd}_{2} \mathrm{O}$ and $1 \mu \mathrm{g}$ of total RNA. Briefly, the RNA, gDNA buffer and RNase-free $\mathrm{ddH}_{2} \mathrm{O}$ were incubated at $42^{\circ} \mathrm{C}$ for $3 \mathrm{~min}$, and then immediately placed on ice. The solutions described above were mixed and incubated at $42^{\circ} \mathrm{C}$ for $15 \mathrm{~min}$ followed by incubation at $95^{\circ} \mathrm{C}$ for $3 \mathrm{~min}$. The reaction solutions were stored at $-20^{\circ} \mathrm{C}$ for use in subsequent experiments. 
Table I. Primers used in the present study.

Primer

DNA sequence (5'-3')

POT1, sense

POT1, antisense

TERT, sense

TERT, antisense

GAPDH, sense

GAPDH, antisense

tel, sense

tel, antisense

$\beta$-globin, sense

$\beta$-globin, antisense

POT1-promoter-1, sense

POT1-promoter-1, antisense

POT1-promoter-2, sense

POT1-promoter-2, antisense
5'-TGTTTCCGTGTTGATGATGTG-3'

5'-TGGCACCTTTGGACCTCTAC-3'

5'-CAAGCTGTTTGCGGGGATTC-3'

5'-TGGCACCTTTGGACCTCTAC-3'

5'-GGAGTCTGGGAAGGGTTG-3'

5'-CAGTTTGGCTTGCTGGTC-3'

5'-GGTTTTTGAGGGTGAGGGTGAGGGTGAGGGTGAGGGT-3'

5'-TCCCGACTATCCCTATCCCTATCCCTATCCCTATCCCTA-3'

5'-GCTTCTGACACAACTGTGTTCACTAGC-3'

5'-CACCAACTTCATCCACGTTCACC-3'

5'-GCAGATCTCCCGCTTCCCCTAAGCTTGCCTCCC-3'

5'-GCAAGCTTGGTTCACACACTGATGGCGCCTGGA-3'

5'-GCAGATCTGCAAGACTCAATGGTGGCA-3'

5'-GCAAGCTTGGGCATAGTCGCTTGTTCT-3'

POT1, protection of telomere 1; TERT, telomerase reverse transcriptase; tel, telomere.

Quantitative (q)PCR for POT1 and hTERT. Primer sequences of POT1, TERT and GAPDH are listed in Table I. The total volume of $20 \mu \mathrm{l}$ of qPCR contained $0.25 \mu \mathrm{M}$ each of forward and reverse primers, $10 \mu 1 \mathrm{SYBR}^{\circledR}$ Premix Ex Taq ${ }^{\mathrm{TM}}$ (Takara Biotechnology Co., Ltd.), $4 \mu \mathrm{l}$ cDNA and $5 \mu 1$ nuclease-free $\mathrm{ddH}_{2} \mathrm{O}$. Three replicates were performed. The thermocycler conditions were as follows: $5 \mathrm{~min}$ at $95^{\circ} \mathrm{C} ; 40$ cycles of $95^{\circ} \mathrm{C}$ for $15 \mathrm{sec}$ and $60^{\circ} \mathrm{C}$ for $30 \mathrm{sec} ; 95^{\circ} \mathrm{C}$ for $5 \mathrm{sec}$; and $60^{\circ} \mathrm{C}$ for 1 min. The reaction was performed using an ABI Prism ${ }^{\circledR} 7300$ Real-Time PCR system (Applied Biosystems; Thermo Fisher Scientific, Inc.). The results were analyzed using the $2^{-\Delta \Delta \mathrm{Cq}}$ method (19) to compare the transcriptional levels of POT1 and hTERT in each sample to the non-compound-treated control. $\Delta \mathrm{Cq}=\mathrm{Cq}(\mathrm{POT} 1$ or hTERT) $\mathrm{Cq}(\mathrm{GAPDH}), \Delta \Delta \mathrm{Cq}=\Delta \mathrm{Cq}$ (target genes in the sample to be tested) $-\Delta \mathrm{Cq}$ (target gene in the control sample). The relative amount of sample template was $2^{-\Delta \Delta \mathrm{Cq}}$.

DNA extraction and $q P C R$ for telomere length. DNA from all non-transfected tumor cells were extracted using the Takara MiniBest Universal Genomic DNA Extraction kit (Version 5.0) according to the manufacturer's protocol. The total PCR volume of $20 \mu \mathrm{l}$ contained $36 \mathrm{ng}$ DNA template, $0.25 \mu \mathrm{M}$ forward and reverse primers each [Table I; tel (1) and $\beta$-globin (20)], $10 \mu 1$ 2X SYBR ${ }^{\circledR}$ Premix Ex Taq and nuclease-free $\mathrm{ddH}_{2} \mathrm{O}$. Three replications were performed. The thermocycling conditions maintained were as follows: $5 \mathrm{~min}$ at $95^{\circ} \mathrm{C} ; 40$ cycles of $95^{\circ} \mathrm{C}$ for $15 \mathrm{sec}$ and $60^{\circ} \mathrm{C}$ for $32 \mathrm{sec} ; 95^{\circ} \mathrm{C}$ for $5 \mathrm{sec}$; and $60^{\circ} \mathrm{C}$ for $1 \mathrm{~min}$. For the present study, telomere (T) and single copy gene ( $\mathrm{S}$; reference gene, $\beta$-globin) PCRs were performed in separate 96 -well plates. The T/S ratio was $\sim 2^{\Delta \mathrm{Cq}} . \Delta \mathrm{Cq}=\mathrm{Cq}($ Telomere $)-\mathrm{Cq}(\beta$-globin $)$. The relative $\mathrm{T} / \mathrm{S}$ ratio (T/S of one sample relative to the $\mathrm{T} / \mathrm{S}$ of another sample) was $2^{-(\Delta \mathrm{Cq} 1-\Delta \mathrm{Cq} 2)}=2^{-\Delta \Delta \mathrm{Cq}} . \Delta \mathrm{Cq} 1$ was the $\mathrm{T} / \mathrm{S}$ ratio of each sample, $\Delta \mathrm{Cq} 2$ was the $\mathrm{T} / \mathrm{S}$ ratio of control DNA. The mean of the relative $\mathrm{T} / \mathrm{S}$ ratio is proportional to telomere length as previously reported $(21,22)$.

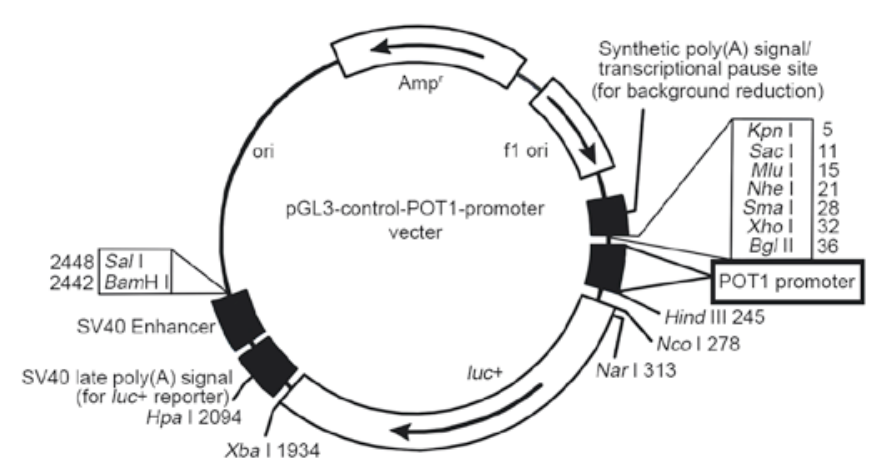

Figure 1. pGL3-Control-POT1-promoter reporter gene carrier. POT1, protection of telomere 1 ; $\mathrm{amp}^{\mathrm{r}}$, ampicillin resistant; ori, origin of replication.

Analysis of the association between POT1 promoter and POT1, hTERT, and telomere length. The association between the POT1 promoter relative activity and POT1 relative expression, hTERT relative expression and the relative of telomere length was performed using partial correlation coefficients and linear regression.

Statistical analysis. All data are representative of three independent experiments and expressed as the mean \pm standard error of the mean. The five different groups being compared in the dual-luciferase report assays were as follows: Blank, non-transfected cells; positive, pGL3-Control-transfected cells; negative, pGL3-Basic-transfected cells; tested, cells transfected with POT1-promoter-1 or POT1-promoter-2. The qPCR tests were performed on the four non-transfected tumor cell lines. Statistical significance was assessed using a two-tailed t-test, linear regression and partial correlation coefficient analysis with SPSS software (version 19.0; IBM Corp., Armonk, NY, USA). P<0.05 was considered to indicate a statistically significant difference. 


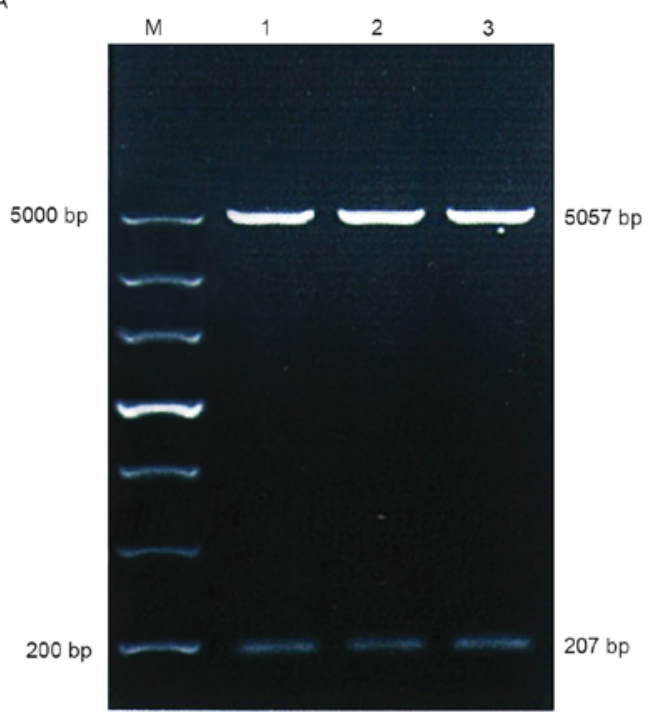

B

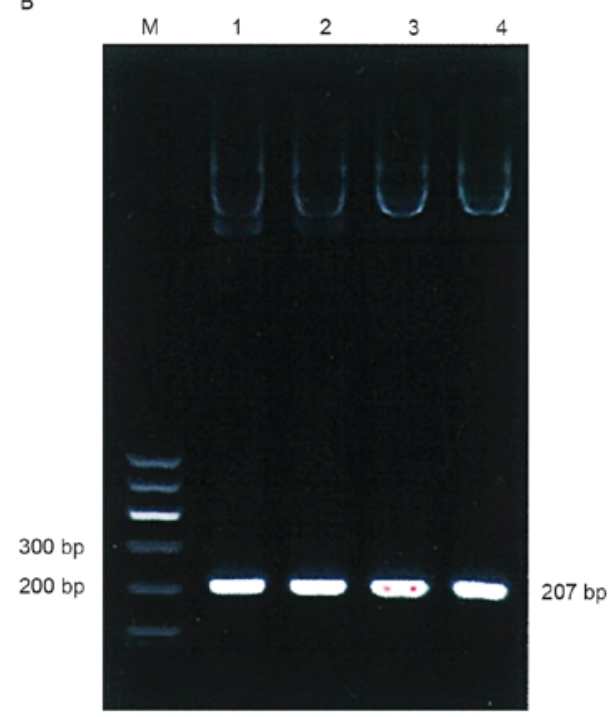

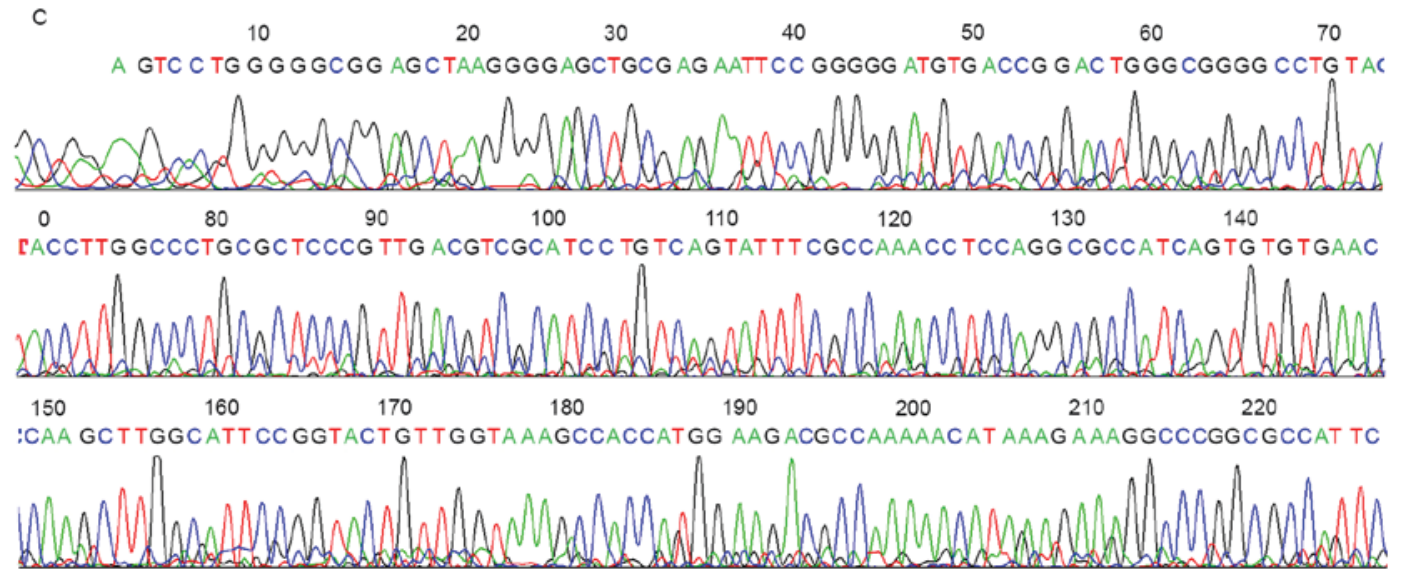

Figure 2. Identification of the recombinant plasmid POT1-promoter-1. (A) Electrophoresis of BglII and HindIII digested products. M, molecular weight marker (200-5,000 bp); lane 1-3, enzyme digestion products (5,057 and 207 bp). (B) Electrophoresis of the PCR products. M, molecular weight marker (100-600 bp); lane 1-4, the PCR products (207 bp) of the POT1-promoter-1 plasmid using primers for POT1-promoter-1. (C) Sequencing results of POT1-promoter-1. POT1, protection of telomere 1 ; PCR, polymerase chain reaction; bp, base pairs.

\section{Results}

Recombinant plasmid construction of pGL3-ControlPOT1-promoter-1. The luciferase reporter gene carrier is demonstrated in Fig. 1. As presented in Fig. 2A, POT1-promoter-1 was identified using BglII and HindIII digestion, the PCR product of the recombinant plasmids (Fig. 2B) and sequencing results (Fig. 2C) indicate that the desired gene was successfully inserted into the plasmid vector pGL3-Control. These results suggest that no base mutation had occurred in the two fragments.

Recombinant plasmid construction of pGL3-ControlPOT1-promoter-2. As presented in Fig. 3A, two bands were observed following double BglII and HindIII digestion. The PCR product of the recombinant plasmids (Fig. 3B) and sequencing results (Fig. 3C) indicate that the desired gene was successfully inserted into pGL3-Control. These results suggest that there were no base mutations in the two fragments.

Results of the dual luciferase reporter gene assay for all four tumor cell lines. Fluc and Rluc vectors were mixed in the ratios
1:1, 10:1, 20:1, 50:1, and 100:1. Following transfection for 12, 24 or $36 \mathrm{~h}$, the highest transfection efficiency was identified using a 50:1 ratio for $24 \mathrm{~h}$. The mixture of Fluc-Rluc (50:1) and the plasmid was co-transfected into the four different types of tumor cells. The transcription activity of the POT1 promoter was then detected using the Dual-Luciferase Reporter assay system $24 \mathrm{~h}$. As presented in Fig. 4, the transcription activity was highest in the POT1-promoter-1 group in all four tumor cell lines. The luciferase activity in the positive, POT1-promoter-1 and POT1-promoter-2 groups were significantly increased compared with the negative group $(\mathrm{P}<0.001$; Fig. 4).

Comparison between the transcription activity of POT1 promoter-1 and -2 reporter genes in different tumor cell lines. pGL3-Control with strong SV40 promoter activity was used as a reference, the ratio between POT1 and SV40 promoter activity provided as an output value of transcription activity. The transcription activities between the POT1 promoter-1 and -2 reporter genes in different tumor cell lines were compared $\left(x^{-} \pm \mathrm{s}, \mathrm{n}=3\right)$. As presented in Fig. 5 and Table II, POT1-promoter-1 exhibited significantly higher transcription activity compared with that of POT1-promoter-2 in all four 


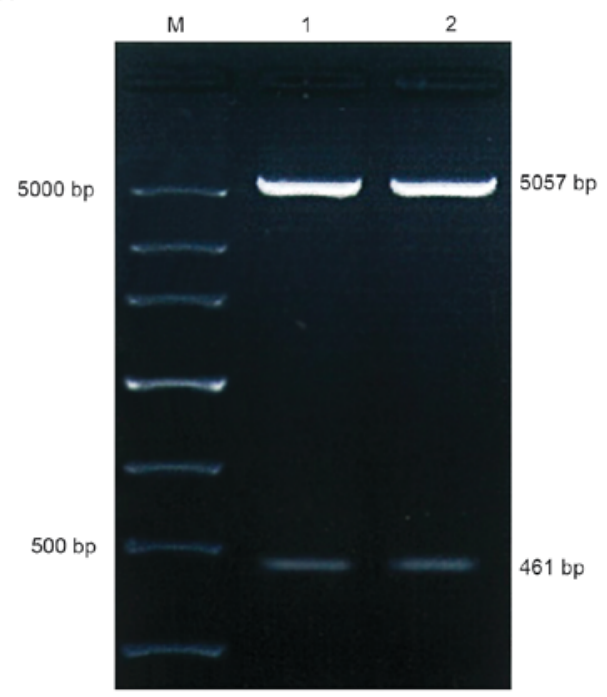

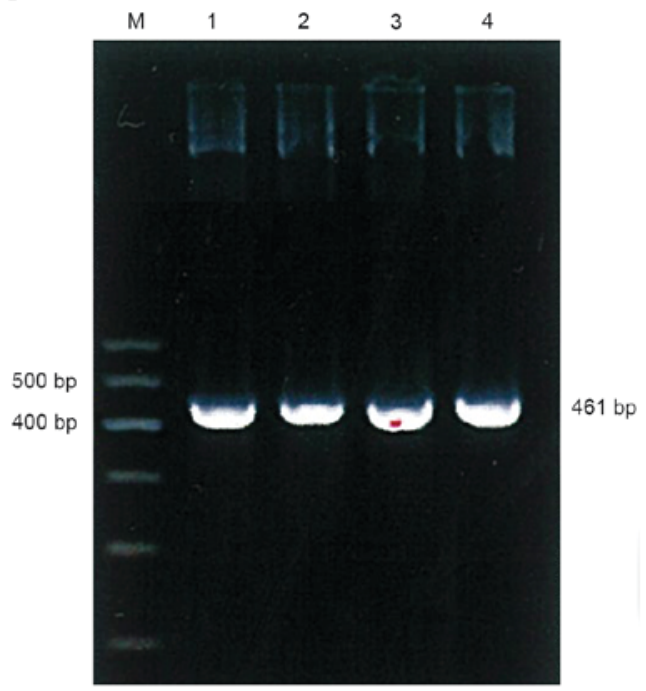

$\begin{array}{llllllll}C & 10 & 20 & 30 & 40 & 50 & 60 & 70\end{array}$ ATAAAAACT CCCAAATAACAT T GT TATCCT T G TAAAT GC T TCCTTGTAAA GACTGCA GTA GG TGCCTA TT TCTTGGAGGA $\frac{d x}{90}$ AG AG AACTG G ACAT TAA A A GAAAGGCTC TGCC TA CAGG AGC TTCG AATC TACCAAAGGG AAGCTCAAAT CCCGCCCAGCG $\frac{1}{10}$ :GACCCGCCCGC T TCCCCTAA GCTTGCCTCCCGCCACGAAAGC TG GAAAGT CACTGGGGG CGGAGCTAAGGGGAGCTG CG

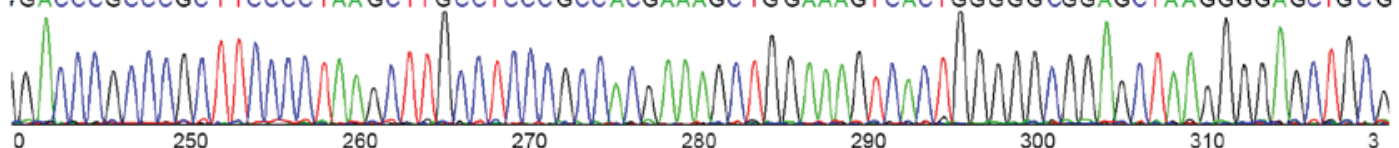
GAAT TCCGGGGG ATG TG ACCGGAC TGGGCGGGGCCTG TACC TT GGCCC TGCGCT CCCGTTGACGTCGCATCCT GT CAGT $\frac{20}{330} \frac{340}{350} \frac{360}{390}$ ATT TCGCCAAACCTCCAGGCGCCATCAGTG TG TGAACCG T TACGCAGC TGGTCCACCGCGGG CGGAGAACAAGCG ACTA

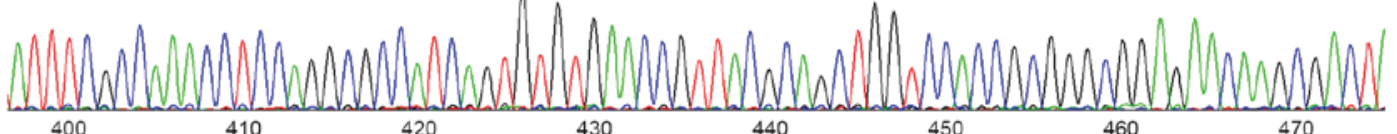
A TGCCCAAGCT TGGCATT CCGGTACTGTTGGTAAAGCCACCATGGAAGACGCCAAAAACATAAAGAAAGGCCCGGG i

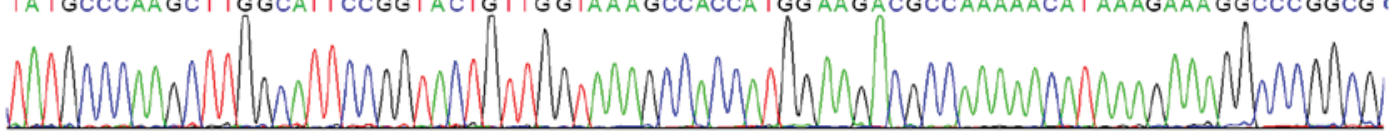

Figure 3. Identification of the recombinant plasmid POT1-promoter-2. (A) Electrophoresis of BglII and HindIII digested products. M, molecular weight marker (200-5,000 bp); lane 1 and 2, enzyme digestion products (5,057 and $461 \mathrm{bp})$. (B) Electrophoresis of the PCR products. M, molecular weight marker (100-600 bp); lane 1-4, the PCR products (461 bp) of the POT1-promoter-2 plasmid using primers for POT1-promoter-2. (C) Sequencing results of POT1-promoter-2. POT1, protection of telomere 1; PCR, polymerase chain reaction; bp, base pairs.

cancer cell lines. Therefore, the following experiments were performed using POT1-promoter-1.

$q P C R$. The POT1 expression, hTERT expression and telomere length of all non-transfected tumor cells were determined using qPCR analysis. All values were normalized to GAPDH and are expressed relative to the HepG2 cell group, which were selected arbitrarily and used as a control group for base comparison. The relative activity of telomerase was indirectly demonstrated by detecting the relative expression of hTERT. The relative $\mathrm{T} / \mathrm{S}$ ratio was used to reflect telomere length.
POT1 expression (Fig. 6A), telomerase activity (Fig. 6B) and telomere length (Fig. 6C) were significantly different across the four types of tumor cells. The highest relative expression of POT1 was in H460 cells, and the lowest in A549 cells. The highest relative activity of telomerase was in A549 and the lowest in HepG2 cells. The relative telomere length was longest in H460 cells and shortest in A549 cells.

Correlation between the POT1 promoter activity and POTI expression, hTERT expression, telomere length. An analysis of the partial correlation coefficients between the POT1 

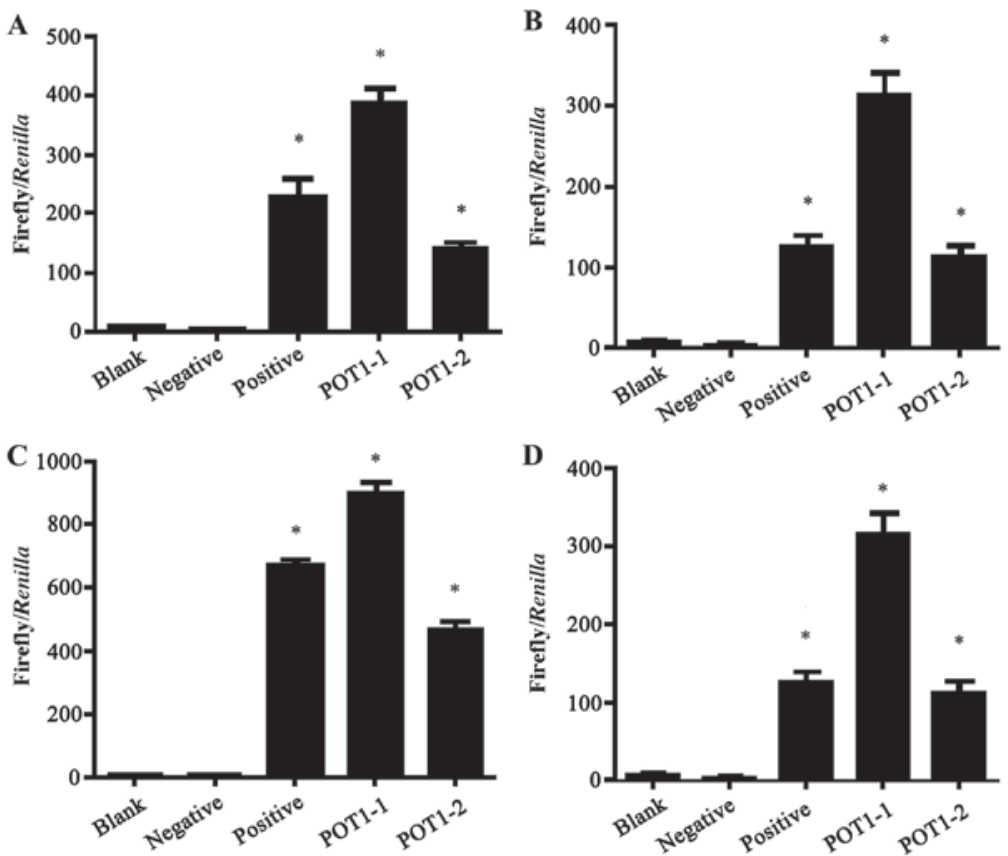

Figure 4. The results of dual-luciferase reporter gene assay of 4 tumor cell lines. POT1 promoter activity was analyzed in A549 (A), H460 (B), HepG2 (C) and HeLa (D) cells by measuring the Firefly/Renilla ratio. Blank, non-transfected cells; positive, pGL3-Control-transfected cells; negative, pGL3-Basic-transfected cells; tested, cells transfected with POT1-promoter-1 (POT1-1) and POT1-promoter-2 (POT1-2). All data are representative of three independent experiments and expressed as the mean \pm standard error of the mean. ${ }^{*} \mathrm{P}<0.001$, compared with pGL3-Basic. POT1, protection of telomere 1.

promoter activity and the three aforementioned factors was performed. Luciferase activity of POT1-promoter-1 was used as a covariate. There was a significant positive correlation between the POT1 promoter activity and POT1 expression (partial correlation coefficient, 0.839) and telomere length (partial correlation coefficient, 0.792) (both $\mathrm{P}<0.05$; Table III and IV), while a significant negative correlation was identified between POT1 promoter activity and hTERT expression (partial correlation coefficient, $-0.700 ; \mathrm{P}<0.05$; Table V). Furthermore,Fig. 7 demonstrates a marked correlation between POT1 promoter activity and POT1 and hTERT expression and telomere length by linear regression analysis (Fig. 7A and C, $\mathrm{P}<0.01$; Fig. $7 \mathrm{~B}, \mathrm{P}<0.05$ ), which are similar to the results of the partial correlation analysis.

\section{Discussion}

Reporter genes are genes with a readily measurable phenotype that may be distinguished in a background of endogenous proteins (23). Reporter gene technology is widely used to monitor the cellular events associated with signal transduction and gene expression (23). The principal advantage of reporter gene technology is its high sensitivity, reliability, convenience and adaptability to large-scale measurements (23). In the present study, two different fragments of the active promoter region of POT1 were obtained through cloning. Luciferase reporter gene vectors that contained different sequence lengths of the POT1 promoter were successfully constructed using DNA recombinant technology. The results of the double enzyme digestion PCR analysis and base sequencing demonstrated that the vector was successfully constructed. Construction of the POT1 promoter reporter gene vector is an effective method for investigating the transcriptional activity of the POT1 promoter

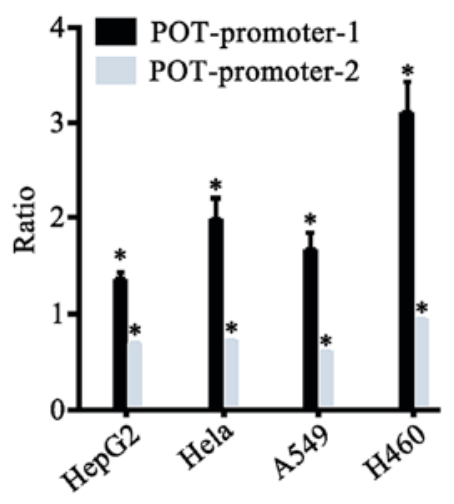

Figure 5. The relative expression activities (\%) of POT1-promoter-1 and POT1-promoter-2 in different types of tumor cells. All data are representative of three independent experiments and expressed as the mean \pm standard error of the mean. ${ }^{*} \mathrm{P}<0.01$, compared with pGL3-Control. POT1, protection of telomere 1; hTERT, human telomerase reverse transcriptase.

and is able to provide a foundation for further studies on the transcriptional regulation mechanism of the POT1 promoter.

The luciferase reporter gene assay is one of the most predominantly used methods for identifying the interaction between a promoter and the genome (24). The dual-luciferase reporter assay system uses a promoter-luciferase-based structure and is used for transient transfection. Tiffen et al (25) confirmed that the expression and associated light-emitting activity of the luciferase gene does not affect the growth of tumor cells. In the present study, POT1-promoter-1 and -2 were separately transfected into four different types of tumor cell lines (HepG2, HeLa, A549 and H460). The transcriptional activity of the POT1-promoter-1 was significantly increased compared with that of POT1-promoter-2. This indicates that compared with POT1-promoter-2 (-370 to $+90 \mathrm{bp})$, 
Table II. The relative activity of the two POT1-promoter regions in four human tumor cell lines.

\begin{tabular}{lcc}
\hline Cell line & $\begin{array}{c}\text { POT1-promoter- } \\
\text { 1/SV40 promoter, } \%\end{array}$ & $\begin{array}{c}\text { POT1-promoter- } \\
\text { 2/SV40 promoter, \% }\end{array}$ \\
\hline HepG2 & $1.34 \pm 0.08^{\mathrm{a}}$ & $0.68 \pm 0.02^{\mathrm{a}}$ \\
HeLa & $1.97 \pm 0.24^{\mathrm{a}}$ & $0.71 \pm 0.06^{\mathrm{a}}$ \\
A549 & $1.65 \pm 0.59^{\mathrm{a}}$ & $0.59 \pm 0.01^{\mathrm{a}}$ \\
H460 & $3.08 \pm 0.33^{\mathrm{a}}$ & $0.92 \pm 0.02^{\mathrm{a}}$ \\
\hline
\end{tabular}

${ }^{a} \mathrm{P}<0.01$, compared with pGL3-Control. POT1, protection of telomere 1 .

Table III. Partial correlation coefficients between POT1 promoter activity and POT1 expression.

\begin{tabular}{lcc}
\hline $\begin{array}{l}\text { Control } \\
\text { variables }\end{array}$ & $\begin{array}{c}\text { POT1 promoter } \\
\text { activity }\end{array}$ & $\begin{array}{c}\text { POT1 } \\
\text { expression }\end{array}$ \\
\hline POT1 promoter activity & 1.000 & 0.839 \\
Correlation & & $0.001^{\mathrm{a}}$ \\
P-value & 0 & 9 \\
df & & 1.000 \\
POT1 expression & 0.839 & \\
Correlation & $0.001^{\mathrm{a}}$ & 0 \\
P-value & 9 & 0 \\
df & 9 & \\
\hline
\end{tabular}

${ }^{\mathrm{a}} \mathrm{P}<0.05$ (2-tailed) compared with POT1 expression. POT1, protection of telomere $1 ; \mathrm{df}$, degrees of freedom.

POT1-promoter-1 (-160 to $+40 \mathrm{bp)}$ may be associated with more positive or negative regulatory elements enabling for participation in POT1 transcription regulation. The confirmation of the POT1 promoter transcriptional activity provided a foundation for further investigation into the underlying POT1 regulatory mechanism.

In the previous 20 years, alterations in telomere length have been established as an important biomarker for cancer and studies into telomere length have aided in developing novel cancer therapies $(26,27)$. The maintenance of telomere length is a necessary condition for the continuous division and immortalization of normal and malignant cells (28). Normally, with each round of cell division small fragments of telomeric DNA are lost and the DNA is shortened eventually leading to cell aging or apoptosis (29). Xin et al (30) suggested that the binding of the POT1-TPP1 complex may recruit telomerase, producing a positive regulatory effect on the extension of telomeres. Izgi et al (31) demonstrated that colorectal cancer cells express a 4.33-fold increase in hTERT compared with normal cells. In addition, a positive correlation between telomerase activity and hPOT1 expression was identified (31). However, certain studies have revealed that POT1 may exhibit a negative regulatory effect, which is able to suppress telomerase duplication and the extension of telomeric DNA:
Table IV. Partial correlation coefficients between POT1 promoter activity and telomere length.

\begin{tabular}{lcc}
\hline $\begin{array}{l}\text { Control } \\
\text { variables }\end{array}$ & $\begin{array}{c}\text { POT1 promoter } \\
\text { activity }\end{array}$ & $\begin{array}{c}\text { Telomere } \\
\text { length }\end{array}$ \\
\hline $\begin{array}{l}\text { POT1 promoter activity } \\
\text { Correlation }\end{array}$ & 1.000 & 0.792 \\
P-value & 0 & $0.004^{\mathrm{a}}$ \\
df & & 9 \\
Telomere length & 0.792 & 1.000 \\
Correlation & $0.004^{\mathrm{a}}$ & \\
P-value & 9 & 0 \\
df & 9 & \\
\hline
\end{tabular}

${ }^{\text {a }}<<0.05$ (2-tailed) compared with telomere length. POT1, protection of telomere 1; df, degrees of freedom.

Table V. Partial correlation coefficients between POT1 promoter activity and hTERT expression.

\begin{tabular}{lcc}
\hline $\begin{array}{l}\text { Control } \\
\text { variables }\end{array}$ & $\begin{array}{c}\text { POT1 promoter } \\
\text { activity }\end{array}$ & $\begin{array}{c}\text { hTERT } \\
\text { expression }\end{array}$ \\
\hline $\begin{array}{l}\text { POT1 promoter activity } \\
\text { Correlation }\end{array}$ & 1.000 & -0.700 \\
P-value & & $0.016^{\mathrm{a}}$ \\
df & 0 & 9 \\
hTERT expression & & 1.000 \\
Correlation & -0.700 & \\
P-value & $0.016^{\mathrm{a}}$ & 0 \\
df & 9 & 0
\end{tabular}

${ }^{\text {a }}<0.05$ (2-tailed) compared with hTERT expression. POT1, protection of telomere 1; hTERT, human telomerase reverse transcriptase; df, degrees of freedom.

In 2008, Churikov and Price (32) demonstrated that the loss of chicken POT1 resulted in exceptionally rapid telomere growth. Furthermore, another study revealed that compared with those cells that overexpressed hTERT alone, telomere length was extended when hPOT1 expression was suppressed and hTERT was overexpressed simultaneously in human skin fibroblasts (33). Furthermore, a negative correlation between the expression levels of telomere-associated proteins (TRF1, TRF2, POT1 and TIN2) and telomere content has been identified in breast cancer cells (34). In addition, telomere shortening has a role in suppressing tumor formation: Zimmermann et al (35) demonstrated the ability for tumor formation was significantly reduced in mice which had both a telomere gene (a dominant-negative mutant of hTERT) and a tumor inhibition gene (P53) knockout, compared with mice with only the tumor inhibition gene knockout. One hypothesis as to explain the observed effects includes the shortening of telomeres, promoting apoptosis or the obstruction of cell 

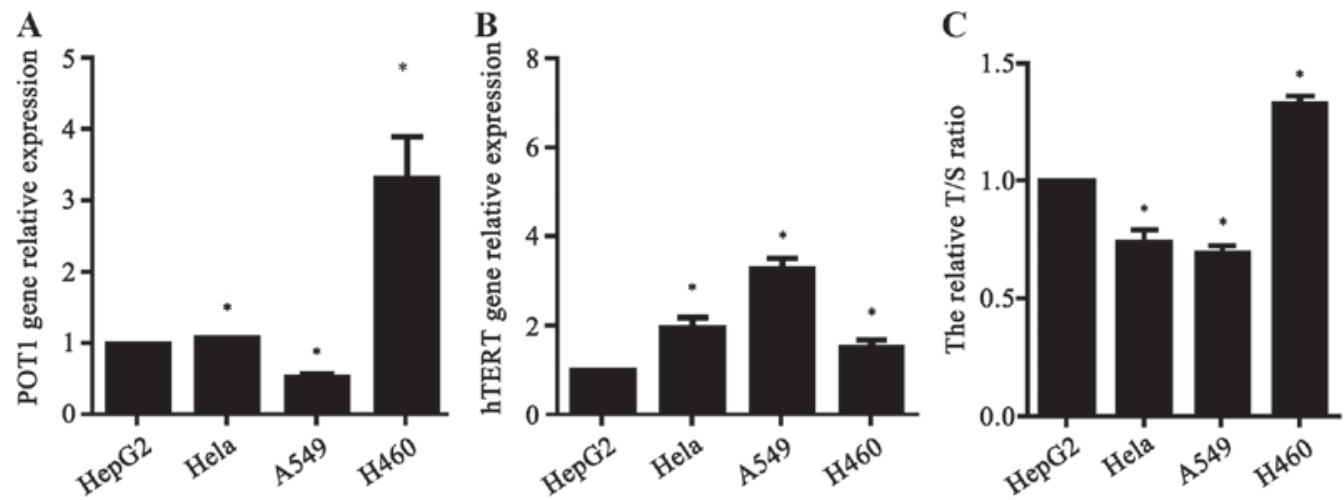

Figure 6. Analysis of POT1 expression, hTERT expression and telomere length in 4 types of non-transfected human tumor cells by quantitative polymerase chain reaction (compared with HepG2 cells). (A) The relative expression of POT1, (B) the relative expression of hTERT and (C) the relative T/S ratio in different human tumor cell lines. ${ }^{*} \mathrm{P}<0.05$, compared with HepG2 cells. All data are representative of three independent experiments and expressed as the mean \pm standard error of the mean. POT1, protection of telomere 1; hTERT, human telomerase reverse transcriptase.
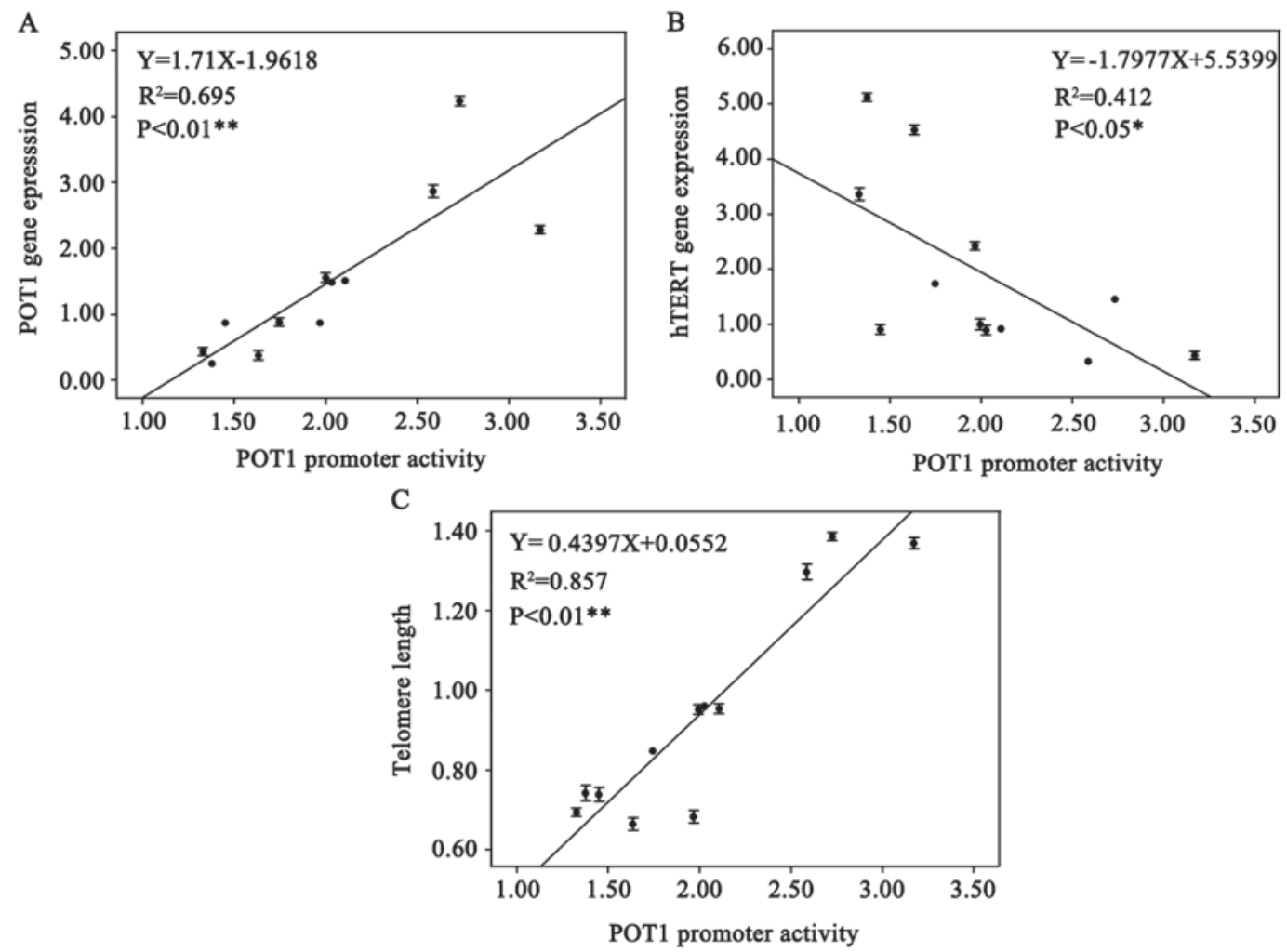

Figure 7. Association between hTERT relative expression, POT1 relative expression levels, telomere length and the POT1 promoter relative activity by linear regression analysis. All of the data for these points were derived from 3 independent experiments of four types of human tumor cells: A549; H460; HepG2; and HeLa. (A) The correlation between POT1 gene and POT1 promoter activity. ${ }^{* *} \mathrm{P}<0.01$. (B) The correlation between hTERT gene and POT1 promoter activity. ${ }^{*} \mathrm{P}<0.05$. (C) The correlation between telomere length and POT1 promoter activity. ${ }^{* *} \mathrm{P}<0.01$. POT1, protection of telomere 1 ; hTERT, human telomerase reverse transcriptase.

cycle progression (35). These results indicated that POT1 has numerous functions in the maintenance of telomere length and telomerase.

Although important results have been demonstrated by numerous previous studies, there are also limitations to the current conclusions. The underlying regulation mechanism of the POT1 promoter and telomere remain to be elucidated. Therefore, it is important to clarify the association among the POT1 promoter, POT1, telomerase and telomere length. In the present study, alterations in the relative expression of POT1 and hTERT, as well as in the telomere length were detected in the non-transfected tumor cells (A549, H460, HeLa, and HepG2) using qPCR. The co-transfection luciferase assay and QPCR results demonstrated that there was a significant negative correlation between the POT1 promoter activity and hTERT expression. A potential explanation for this observation is the expression of hTERT was affected primarily by regulatory elements of the hTERT promoter. However, a significantly positive correlation was identified between the activity of the POT1 promoter, and the expression of POT1 or telomere 
length. Therefore, this indicates that POT1 promoter activity and POT1, as well as telomere length, may become potentially useful biomarkers for cancer in the future. Furthermore, these results preliminarily demonstrate that the POT1 promoter may be involved in the regulation of telomere length.

In conclusion, the results of the present study have identified a potential association between the POT1 promoter activity, POT1 and telomere length. Further experiments using numerous human tumor types are required for elucidating the underlying regulatory mechanism of the POT1 promoter and identified useful tumor biomarkers.

\section{Acknowledgements}

The present study was supported by the First Science and Technology Program of Guangdong province (grant no. 2008B030301023) and the Science and Technology Program of Higher Learning Institutions in Dongguan (grant nos. 200910815264 and 2012108102016).

\section{References}

1. Lau LM, Dagg RA, Henson JD, Au AY, Royds JA and Reddel RR: Detection of alternative lengthening of telomeres by telomere quantitative PCR. Nucleic Acids Res 41: e34, 2013.

2. Baumann P, Podell E and Cech TR: Human Pot1 (protection of telomeres) protein: Cytolocalization, gene structure, and alternative splicing. Mol Cell Biol 22: 8079-8087, 2002.

3. Blasco MA, Lee HW, Hande MP, Samper E, Lansdorp PM, DePinho RA and Greider CW: Telomere shortening and tumor formation by mouse cells lacking telomerase RNA. Cell 91: 25-34, 1997.

4. van Steensel B, Smogorzewska A and de Lange T: TRF2 protects human telomeres from end-to-end fusions. Cell 92: 401-413, 1998

5. Lee HW, Blasco MA, Gottlieb GJ, Horner JW II, Greider CW and DePinho RA: Essential role of mouse telomerase in highly proliferative organs. Nature 392: 569-574, 1998.

6. Nguyen BN, Elmore LW and Holt SE: Mechanism of dominant-negative telomerase function. Cell Cycle 8: 3227-3233, 2009.

7. Ozturk S, Sozen B and Demir N: Telomere length and telomerase activity during oocyte maturation and early embryo development in mammalian species. Mol Hum Reprod 20: 15-30, 2014.

8. Meyerson M, Counter CM, Eaton EN, Ellisen LW, Steiner P, Caddle SD, Ziaugra L, Beijersbergen RL, Davidoff MJ Liu Q, et al: hEST2, the putative human telomerase catalytic subunit gene, is up-regulated in tumor cells and during immortalization. Cell 90: 785-795, 1997.

9. Nakamura TM, Morin GB, Chapman KB, Weinrich SL, Andrews WH, Lingner J, Harley CB and Cech TR: Telomerase catalytic subunit homologs from fission yeast and human. Science 277: 955-959, 1997.

10. O'Sullivan JN, Bronner MP, Brentnall TA, Finley JC, Shen WT, Emerson S, Emond MJ, Gollahon KA, Moskovitz AH, Crispin DA, et al: Chromosomal instability in ulcerative colitis is related to telomere shortening. Nat Genet 32: 280-284, 2002.

11. Plentz RR, Schlegelberger B, Flemming P, Gebel M, Kreipe H, Manns MP, Rudolph KL and Wilkens L: Telomere shortening correlates with increasing aneuploidy of chromosome 8 in human hepatocellular carcinoma. Hepatology 42: 522-526, 2005.

12. Loayza D and De Lange T: POT1 as a terminal transducer of TRF1 telomere length control. Nature 423: 1013-1018, 2003.

13. Wang F, Podell ER, Zaug AJ, Yang Y, Baciu P, Cech TR and Lei M: The POT1-TPP1 telomere complex is a telomerase processivity factor. Nature 445: 506-510, 2007.

14. Latrick CM and Cech TR: POT1-TPP1 enhances telomerase processivity by slowing primer dissociation and aiding translocation. EMBO J 29: 924-933, 2010.
15. Baumann P and Cech TR: Pot1, the putative telomere end-binding protein in fission yeast and humans. Science 292: 1171-1175, 2001.

16. Veldman T, Etheridge KT and Counter CM: Loss of hPot1 function leads to telomere instability and a cut-like phenotype. Curr Biol 14: 2264-2270, 2004.

17. Armbruster BN, Linardic CM, Veldman T, Bansal NP, Downie DL and Counter CM: Rescue of an hTERT mutant defective in telomere elongation by fusion with hPot1. Mol Cell Biol 24: 3552-3561, 2004.

18. Colgin LM, Baran K, Baumann P, Cech TR and Reddel RR: Human POT1 facilitates telomere elongation by telomerase. Curr Biol 13: 942-946, 2003.

19. Livak KJ and Schmittgen TD: Analysis of relative gene expression data using real-time quantitative PCR and the 2(-Delta Delta C(T)) method. Methods 25: 402-408, 2001.

20. Prather AA, Puterman E, Lin J, O'Donovan A, Krauss J, Tomiyama AJ, Epel ES and Blackburn EH: Shorter leukocyte telomere length in midlife women with poor sleep quality. J Aging Res 2011: 721390, 2011.

21. Zee RY, Michaud SE, Germer S and Ridker PM: Association of shorter mean telomere length with risk of incident myocardial infarction: A prospective, nested case-control approach. Clin Chim Acta 403: 139-141, 2009.

22. Lapham K, Kvale MN, Lin J, Connell S, Croen LA, Dispensa BP, Fang L, Hesselson S, Hoffmann TJ, Iribarren C, et al: Automated assay of telomere length measurement and informatics for 100,000 subjects in the genetic epidemiology research on adult health and aging (GERA) cohort. Genetics 200: 1061-1072, 2015.

23. Naylor LH: Reporter gene technology: The future looks bright. Biochem Pharmacol 58: 749-757, 1999.

24. Miraglia LJ, King FJ and Damoiseaux R: Seeing the light: Luminescent reporter gene assays. Comb Chem High Throughput Screen 14: 648-657, 2011.

25. Tiffen JC, Bailey CG, Ng C, Rasko JE and Holst J: Luciferase expression and bioluminescence does not affect tumor cell growth in vitro or in vivo. Mol Cancer 9: 299, 2010.

26. Wentzensen IM, Mirabello L, Pfeiffer RM and Savage SA: The association of telomere length and cancer: a meta-analysis. Cancer Epidemiol Biomarkers Prev 20: 1238-1250, 2011.

27. Zhang CL, Chen XH, Li L, Zhou Y, Wang C and Hou S: The association between telomere length and cancer prognosis: Evidence from a meta-analysis. PLoS One 10: e0133174, 2015.

28. Gilson E and Londoño-Vallejo JA: Telomere length profiles in humans: All ends are not equal. Cell Cycle 6: 2486-2494, 2007.

29. Ju Z and Lenhard Rudolph K: Telomere dysfunction and stem cell ageing. Biochimie 90: 24-32, 2008.

30. Xin H, Liu D, Wan M, Safari A, Kim H, Sun W, O'Connor MS and Songyang Z: TPP1 is a homologue of ciliate TEBP-beta and interacts with POT1 to recruit telomerase. Nature 445: 559-562, 2007.

31. Izgi A, Gunal A, Yalcin S and Gunduz U: Telomere 1 (POT1) gene expression and its association with telomerase activity in colorectal tumor samples with different pathological features. Biomed Pharmacother 68: 841-846, 2014.

32. Churikov D and Price CM: Pot1 and cell cycle progression cooperate in telomere length regulation. Nat Struct Mol Biol 15: 79-84, 2008.

33. Possemato R, Timmons JC, Bauerlein EL, Wada N, Baldwin A, Masutomi K and Hahn WC: Suppression of hPOT1 in diploid human cells results in an hTERT-dependent alteration of telomere length dynamics. Mol Cancer Res 6: 1582-1593, 2008.

34. Butler KS, Hines WC, Heaphy CM and Griffith JK: Coordinate regulation between expression levels of telomere-binding proteins and telomere length in breast carcinomas. Cancer Med 1: 165-175, 2012.

35. Zimmermann S, Biniossek ML, Maurer C, Münzer P, Pantic M, Veelken $\mathrm{H}$ and Martens UM: Proteomic profiling in distinct cellular compartments of tumor cells reveals p53-dependent upregulation of S100A6 upon induction of telomere dysfunction. Proteomics 9: 5175-5187, 2009. 